\title{
Rendición de cuentas y legitimidad: una propuesta de tipología de los sistemas políticos autocráticos y democráticos
}

\author{
Oliver Soto Sainz ${ }^{1}$
}

Recibido: 01/02/2020 / Aceptado: 10/03/2020

Resumen. En este artículo pretendemos presentar el concepto de sistema político como la base para la elaboración de una tipología empíricamente útil para dividir los sistemas políticos en categorías que nos permitan extraer conclusiones sobre su funcionamiento. El concepto de sistema nos engloba el marco de objetivos, normas y estructuras en el que se desenvuelven los actores para dar respuestas a las demandas, incorporando tanto el marco normativo, como la interacción de los actores con objetivos, normas y estructuras y de éstos a su vez con las demandas. En este estudio identificamos dentro del enfoque sistémico dos momentos: el sistema como procesamiento de demandas y el sistema como productor de resultados. Empleamos el sistema como procesamiento de demandas como centro de nuestro ejercicio clasificatorio, basado en dos nociones básicas para la Ciencia Política, la rendición de cuentas y la legitimidad.

Centrando nuestro análisis en el modo en que se procesan las demandas hemos aplicado tres criterios de clasificación: el número efectivo de actores y grupos de intermediación y articulación de demandas ante los que responde el sistema, el carácter civil o militar de los dirigentes del sistema y el principio de legitimidad frente a los apoyos al sistema. Finalmente, en este artículo procedemos a aplicar las categorías resultantes en todos los países entre 1960 y 2006, comparándolo con otras clasificaciones.

Palabras clave: Accountability (rendición de cuentas), legitimidad, democracia, autocracia, sistemas políticos comparados.

[en] Accountability and legitimacy: towards a new proposal of typology of the authocratic and democratic systems

\begin{abstract}
In this article, we intend to introduce the concept of political system as the basis for the development of an empirically useful tool to divide the political systems in categories that allow us to draw conclusions. The concept of system incorporates the framework of objectives, rules and structures in which actors perform in order to respond to the demands (inputs) of the population, incorporating both the regulatory framework, as the interaction of the actors with goals, standards and structures and the feedback process. In this study, we identified within the systemic approach two moments: the system as demands processing (inputs) and the system as producing results (outputs). We focus in this article in the systems as input processing in order to create our typology, based on two basic concepts for Political Science, accountability and legitimacy.

Focusing our analysis on how claims are processed we applied three classification criteria: the actual number of actors and groups of articulation of demands beyond which the system is held accountable, the principle of legitimacy and civilian or military nature of the system leadership. Finally, in this article we proceed to apply the categories resulting in all countries between 1960 and 2006 , concentrating more in the comparative analysis with other large-scale classifications.
\end{abstract}

Keywords: Coproduction; Citizen engagement; Public administration; Governance.

Sumario. 1. Introducción. 2. Marco teórico: del concepto de régimen político al de sistema político. 2.1. El concepto de régimen político. 2.2. El concepto de sistema político en relación con el de régimen político. 3. Marco metodológico. 3.1. Diseño del estudio: Enfoque sistémico. 3.2. Criterios para una tipología de los sistemas políticos. 3.3. Operacionalizando las variables de clasificación. 3.4. Marco espacial y temporal. 4. Clasificación de los sistemas políticos en perspectiva comparada. 4.1. Resultado de la aplicación de las categorías de análisis. 4.2. Comparación de la tipología con la desarrollada por otros autores. 5. Conclusiones.

Cómo citar: Soto Sainz, O. (2020): Rendición de cuentas y legitimidad: una propuesta de tipología de los sistemas políticos autocráticos y democráticos, en Cuadernos de Gobierno y Administración Pública 7-1, 27-39. 


\section{Introducción}

En Ciencia Política el uso de los conceptos de sistema político y régimen político está muy extendido, pero carecemos de una base común o una definición marco largamente aceptada como pueda ocurrir en otras ocasiones, lo que lleva a que ambos conceptos sean confundidos o usados indistintamente (Paniagua, 1990: 202; Morlino, 1988: 129). Su uso varía de autor a autor, si bien muchas veces esto parte más bien de implícitos metodológicos o epistemológicos, que de referencias explícitas en los propios textos. Es más, podemos encontrarnos con la paradoja de que los autores usen exactamente el mismo vocablo cuando en realidad se refieren a realidades bien distintas. Además, los conceptos de sistema político y régimen político son de uso corriente no sólo en las Ciencias Sociales, sino en el lenguaje no científico, de manera que lo que se entiende por unos o por otros no sólo es muy dispar, sino que está sujeto a los cambios en las percepciones sociales. El uso común de los términos también ha provocado desplazamientos semánticos a lo largo del tiempo. Así, el régimen político, que en cierta forma aparece en los vocablos modernos como una categorización y oposición al Antiguo Régimen (Paniagua, 1990: 201), ha estado asociado a la definición de organizaciones políticas no democráticas, de manera que resulte habitual el vocablo régimen autoritario y muchos menos el de régimen democrático. Estos fenómenos pueden llevar a confusión, por lo que pretendemos clarificar en este artículo los aspectos relativos a la denominación de régimen y sistema para ver qué aporta cada uno de ellos.

Por otra parte, este problema sobre las denominaciones es aún más agudo cuando se trata el apartado de las tipologías, donde existen muchas alternativas desarrolladas por los autores que han tratado la materia, en ocasiones concurrentes en ciertos aspectos y en otras completamente divergentes. En este artículo exploramos las distintas tipologías que existen de sistemas políticos para poder entender mejor cómo se articulan y elaborar una tipología propia de los sistemas políticos.

Para acometer lo anterior, en primer lugar, en el marco teórico contrapondremos los conceptos de sistema y régimen político, viendo cómo se han ido entremezclando, qué los asemeja y qué los diferencia. En segundo lugar, en el apartado metodológico nos detendremos a explicar cómo hemos elaborado una clasificación de los sistemas políticos propia que se adapte mejor a las necesidades de esta investigación. En tercer lugar, hemos comparado nuestra investigación con la realizada por otros autores y la aplicamos al universo de casos entre los años 1960 y 2006. Finalmente presentamos una breve recapitulación de resultados.

\section{Marco teórico: del concepto de régimen político al de sistema político}

Dentro de la Ciencia Política la preocupación por la definición y clasificación de la organización política humana ha estado en su base y ha sido el motivo de su desarrollo. La fundamentación misma como disciplina hunde sus raíces en las elaboraciones teóricas y empíricas de autores tan remotos como Platón o Aristóteles, quienes ya se dedicaron a la tarea de definir teóricamente y catalogar empíricamente los regímenes políticos de su época. Si quisiéramos tratar este tema de manera extensa, merecería por sí mismo de un estudio aparte de mayor entidad, hecho que se escapa de los objetivos y alcance de este artículo. Aun así, y precisamente por el profundo calado que este tema tiene en el desarrollo de la Ciencia Política, y especialmente en el ámbito de la Política Comparada, conviene mostrar una panorámica general de las definiciones que los autores modernos ofrecen sobre el tema para poder ilustrar mejor nuestro enfoque y categorización.

Una lectura de la bibliografía más moderna relacionada con la clasificación de las unidades políticas nos muestra con frecuencia dos conceptos, régimen y sistema político, que muchas veces se usan indistintamente y, en otras ocasiones, de manera diferenciada. La divergencia y convergencia de ambos términos procede en gran parte de su distinto origen (Vargas, 1998: 176). Mientras que el concepto de régimen político se inserta dentro de la tradición francesa de pensamiento $\mathrm{y}$, en general, del pensamiento continental, el concepto de sistema político tiene una mayor inspiración anglosajona, aparecido entre los años treinta y sesenta y desarrollado fundamentalmente en los Estados Unidos con las aportaciones de Easton (1953) y Almond (1966). Asimismo, difieren en etimología. El término régimen procede del latín (régimen), que significa dirección, comparte raíz con el vocablo rex (rey), generado a partir del verbo rego, (-is, -ere, regi, rectum), que significa regir, dirigir, gobernar. Por su parte, el término sistema procede del griego $(\sigma v ́ \sigma \tau \eta \mu \alpha)$, que significa reunir de manera ordenada. De cara a lograr una mayor precisión terminológica y evitar confusiones derivadas del uso común indistinto entre los diversos autores procederemos a delimitar cada uno de ellos y ofrecer la esfera propia que atribuimos a cada concepto ${ }^{2}$.

\subsection{El concepto de régimen político}

De acuerdo con Skaaning (2006), se pueden detectar tres tipos distintos de definiciones del concepto de régimen, con varios subtipos dentro de cada una de ellas. La primera de ellas presta atención exclusivamente al rol que juegan los actores políticos. La segunda de las definiciones centra su atención en las instituciones. La tercera de las definiciones considera que existe un continuum en los regímenes políticos desde las más abiertas democracias a las más cerradas autocracias. Pasaremos a continuación a relatar cada uno de los tipos y subtipos.

El primer tipo de definiciones presta especial atención a los actores y, en concreto, a la coalición domi-

No obstante, esta precisión, en aquellos apartados en los que hemos mencionado la contribución de un autor concreto, se ha respetado la propia terminología que dicho autor emplea. Si bien esto se puede prestar a cierta confusión, no es menos cierto que en esta área de la Política Comparada no existe un patrón mayoritario único. 
nante. Una de las primeras expresiones más características de este tipo de definición podemos encontrarla en el Manifiesto Comunista. Allí Engels y Marx señalan que "el gobierno del Estado no es más que la junta que administra los negocios comunes de la clase burguesa ${ }^{3 "}$. En línea con esto encontramos varias formulaciones similares, dependiendo de si se pone énfasis en los actores o en las estructuras. Michael Mann (1993: 18) considera que un régimen político es "una alianza de actores de poder ideológicos, económicos, y militares dominantes, coordinado por los gobernantes del Estado". Este tipo de definiciones que ponen el foco de atención sobre una clase dominante también incorporan las estructuras de poder, pero siempre desde la perspectiva de su servicio a dicha clase dominante. Así pues, el análisis institucional queda oscurecido en un segundo plano frente a análisis sobre comportamiento, intereses y estrategias de los actores.

El segundo grupo de definiciones centra su atención en las instituciones. A pesar de su foco común en las instituciones, hay varios modos de entender éstas y el alcance del concepto de régimen político (Vargas, 1998: 157). En sentido restringido algunos autores las asimilan a las instituciones pertenecientes al Estado y al modo como se relacionan entre sí y con la sociedad. Una perspectiva más formal define y clasifica los regímenes políticos atendiendo exclusivamente a las normas jurídicas que los sustentan. El régimen político se identifica así con las normas que lo rigen y de éste su máxima expresión es la Constitución. En segundo lugar, como evolución de la perspectiva anterior, otro tipo de definiciones enfatizan el elemento formal, pero añaden el elemento de los valores que inspiran el régimen. En esta línea Lucio Levi (en Bobbio, Matteuci y Pasquino, 1997) define el régimen político como "el conjunto de las instituciones que regulan la lucha por el poder y el ejercicio del poder y de los valores que animan la vida de tales instituciones". En tercer lugar, observamos una perspectiva que, sin dejar de atender a los aspectos formales, añade a éstos elementos no formales, haciendo las fronteras con los aspectos formales más permeables. En este sentido Duverger (1981: 7) define el régimen político como "la forma que en un grupo social dado toma la distinción esencial de gobernantes y gobernados". En este autor, la noción de régimen político abarca no sólo a las instituciones formales sino a los partidos políticos, la opinión pública, el sistema electoral, entre otros. Esto le lleva a concluir que la expresión de régimen político es "prácticamente sinónima" de la de sistema político (Duverger: 1970: 65).

El tercer grupo de definiciones se centra en la existencia de una continuidad en los regímenes políticos desde las más abiertas democracias a las más cerradas

Curiosamente, esta frase registra mucha disparidad en las traducciones dependiendo de la edición que se maneje. Así también podemos leer:

"El Gobierno moderno no es sino un Comité administrativo de los negocios de la clase burguesa".

"El poder público es pura y simplemente, un consejo que gobierna los intereses colectivos de la clase burguesa".

"El gobierno del Estado moderno no es más que una junta que administra los negocios comunes de toda la clase burguesa". autocracias. Carece de interés para estas perspectivas definir el régimen pues de lo que se trata es de ver la variación en ciertos aspectos de los regímenes políticos. Por ejemplo, la escala Polity distingue en el grado de liberalización de un sistema, yendo desde -10 , que significaría la mayor autocracia, hasta 10 , que significaría una democracia plena y consolidada (Marshall y Jaggers, 2007). Por su parte, el índice Freedom House (2014) realiza un panel anual con varios expertos en los que se pregunta sobre aspectos relacionados con las libertades políticas, civiles y de prensa con el objetivo de clasificar los países en libres, parcialmente libres o no libres. Junto al índice de democracia desarrollado por The Economist Intelligence Unit (2014) encontramos otros índices de democracia que siguen líneas similares (de Miguel y Martínez-Dordella, 2014).

\subsection{El concepto de sistema político en relación con el de régimen político}

El concepto de sistema político se entrecruza con el concepto de régimen político, llegando algunos autores a identificar ambos como sinónimos. Si bien existen también diversas definiciones de lo que es un sistema político, en este caso sí disponemos de formulaciones claras realizadas por Easton (1953) y Almond (1966), entre otros, siempre en una línea similar. De acuerdo con Easton (2006) "puede denominarse sistema político a aquellas interacciones por medio de las cuales se asignan autoritariamente [con autoridad] valores en una sociedad; esto es lo que lo distingue de otros sistemas de su medio". En este conjunto de interacciones el sistema político se caracteriza porque recibe una serie de entradas (inputs) que se visualizan en la forma de demandas y/o apoyos, que se encarga de procesar para producir unos resultados (outputs) vinculantes que inciden a su vez en las demandas y los apoyos generando un proceso de retroalimentación (feedback) que alimenta el sistema y reinicia el proceso.

La primera pregunta que surge con respecto al concepto de régimen y de sistema es clara. Siendo conceptos tan colindantes, ¿son excluyentes? Algunos autores (Badie et al., 1996; Chevalier, 1996) han explicado que cabe una esfera propia para cada uno de los conceptos, siendo uno más inclusivo que el otro. Así, "la noción de régimen político sirve para dar cuenta de la manera específica como son organizados los poderes públicos, es decir, su modo de designación, sus competencias respectivas y las reglas jurídicas y políticas que gobiernan sus relaciones" (Badie et al., 1996: 238). Consideran que debe distinguirse con respecto al concepto de sistema político que tachan de "más amplio", pues "incluye no solamente la organización constitucional de los gobernantes, sino también otros actores y otros procesos tales como, por ejemplo, el régimen de partidos, las libertades públicas y los medios de comunicación, los mecanismos de socialización política de los ciudadanos, etc" (Badie et al., 1996: 238). Por tanto, son conceptos diferenciables. Cabe pues preguntarse si existe alguna esfera propia para el concepto de régimen partiendo desde esta 
perspectiva sistémica. A este respecto ambos conceptos pueden entroncar de la siguiente manera según Dennis y Easton (1967: 25):

En su concepción más amplia, un sistema político es un medio a través del cual las necesidades de los miembros de una sociedad se convierten en decisiones vinculantes. Para sostener un proceso de conversión de este tipo una sociedad debe proporcionar un contexto relativamente estable para la interacción política, un conjunto de reglas básicas para la participación en todas las partes del proceso político. Podemos describir este contexto de diversas maneras como un orden constitucional, un conjunto de normas fundamentales, o los procedimientos habituales para la solución de diferencias. Pero independientemente de cómo se define este contexto, por lo general incluye tres elementos: algunas restricciones mínimas sobre los objetivos generales de sus miembros, las reglas o normas que rigen el comportamiento y estructuras de autoridad a través del cual los miembros del sistema actúan para confeccionar e implementar los resultados políticos. A estos objetivos, normas y estructuras podemos darle el nombre tradicional de "régimen político" o de orden constitucional en el sentido más amplio y no jurídico de la frase.

De esta manera observamos que el régimen político constituye una parte importante del sistema político, llamada a durar si dicho sistema tiene visos de permanencia. Es el conjunto de objetivos globales, reglas básicas de funcionamiento y estructuras para la toma de decisiones. Es así un soporte estable para la conversión de las demandas en resultados vinculantes, elemento fundamental que caracteriza al sistema político. En este sentido, podemos añadir que, si bien el régimen se refiere especialmente a los valores y las estructuras e instituciones del poder, el sistema político incorpora además los actores y procesos que operan en la arena política e interactúan entre sí.

A diferencia de Easton, quien distingue sólo dos procesos, Almond y Powell (1981) consideran que "la teoría de sistemas divide los procesos de interacción en tres fases: input o entrada, conversión y output o salida". Vallès (2013), por su parte, hace corresponder dicha división con tres dimensiones de la política: proceso, estructura y resultado. Cada dimensión se corresponde con un aspecto que en inglés es distinguible por el uso de un término distinto, pero que en castellano no tiene un correlato tan exacto. Así diferencia la política como proceso (Politics) que es cuando "observamos ante todo una secuencia de conductas individuales y colectivas que se encadenan dinámicamente" (Vallès, 2013: 45); la política como estructura (Polity), que es cuando "fijamos nuestra atención en el modo estable en que una comunidad determinada organiza sus actuaciones políticas" (Vallès, 2013: 45); y la política como resultado (Policy), que es cuando "el punto de atención principal lo constituyen las respuestas que la combinación de proceso y estructura da a cada conflicto" (Va1lès, 2013: 46).

\section{Marco metodológico}

Tal y como comentábamos en la introducción, el objetivo de este trabajo es elaborar una tipología que clasifique los sistemas políticos, tanto democráticos como autocráticos, teniendo en cuenta el debate producido en el seno de la Política Comparada con respecto a la dicotomía entre sistema y régimen político. Gremy y Le Moan (1977: 15) señalan que "elaborar una tipología consiste en distinguir, en el seno de un conjunto de unidades (sean éstos individuos, grupos de individuos, hechos sociales, etc.), los grupos que se puedan considerar como homogéneos desde un cierto punto de vista". Según estos mismos autores, una tipología debe satisfacer dos condiciones. Por un lado, debe ser exhaustiva, es decir, que cada caso de análisis debería poder ser clasificado en alguna de las categorías elaboradas. Por el otro, las categorías de la tipología deben ser exclusivas, es decir, que cada unidad estudiada sólo puede ser agrupada en uno de los grupos empleados para la clasificación (Gremy y Le Moan, 1977: 15).

En este apartado metodológico, expondremos en primer lugar el enfoque sistémico que vamos a adoptar para abordar la clasificación de los sistemas políticos que nos proponemos. En segundo lugar, abordaremos el modo en que se planteará la clasificación propia de los sistemas políticos. En tercer lugar, operacionalizaremos las variables y definiremos las categorías de análisis. Por último, expondremos nuestro marco temporal y espacial.

\subsection{Diseño del estudio: enfoque sistémico}

Partiendo de las definiciones que hemos visto en el marco teórico, dentro del enfoque sistémico podemos detectar tres momentos clave en el desarrollo del sistema político. El primero de ellos es el procesamiento de las entradas, es decir, con qué tipo de apoyos cuenta el sistema y cómo se canalizan las demandas; el segundo es la producción de resultados, es decir, acciones (o inacciones) vinculantes destinadas a responder a las demandas; el tercero es el efecto de retroalimentación que vuelve a insuflar el proceso. Detectados estos tres elementos, la cuestión relevante para esta investigación es ver cuáles nos resultan más útiles de cara a la operacionalización de los conceptos

Primero, cabe dilucidar si es más pertinente para esta investigación el uso del concepto de régimen político o el de sistema político. Dada la perspectiva sistémica que empleamos, el régimen político describe sólo una parte del proceso político y nos muestra el marco de objetivos, normas y estructuras en el que se desenvuelven los actores para dar respuestas a las demandas. Pero, como hemos visto en otros autores que definían régimen político latu sensu, hay elementos importantes del juego político que se quedarían fuera si atendemos exclusivamente al marco normativo (ya sea formal e informal), como es la interacción de los actores con objetivos, normas y estructuras. Así pues, en nuestro caso optaremos por el concepto de sistema político en el sentido menos restrictivo, es decir, con toda su complejidad y carácter abstracto y en consecuencia inclusivo. 
Segundo, adoptada la perspectiva del sistema político, debemos determinar de qué manera vamos a aproximarnos a la misma dentro de las tres aproximaciones (proceso, resultado, estructura) que hemos señalado. El objetivo, como se ha apuntado desde un principio, es que estos conceptos nos sean de utilidad para dividir la realidad política y, a partir de dicha división, generar categorías de análisis empíricamente verificables que nos permitan clasificar la realidad de los casos. Dividiendo la realidad en múltiples compartimentos será más sencillo realizar inferencias. Por ello atenderemos a los tipos de divisiones que pueden realizarse partiendo de estas categorías.

De acuerdo con Easton hay dos elementos que se han detectado como más relevantes dentro del sistema: por la vía de las entradas (inputs) y por la vía de los resultados (outcomes) y retroalimentación. En primer lugar, tenemos el procesamiento de las entradas. Dentro de esta perspectiva podría ponerse el acento tanto en la procedencia de los apoyos al sistema como en el modo en que se procesarán las demandas. Si se atiende a la procedencia de los apoyos, se trata de ver qué grupos sociales sostienen el sistema con su apoyo. Esta perspectiva implica subrayar la composición social de las coaliciones dominantes. Si se atiende a las demandas, se trata de observar cómo se procesan las demandas y de qué manera éstas pueden llegar a ser resultados. Esta perspectiva implica destacar los mecanismos de conversión de las demandas en resultados y ante quiénes responden efectivamente quienes controlan las estructuras de decisión.

En segundo lugar, nos encontramos ante los resultados del sistema político y la retroalimentación. En este aspecto nos encontramos con las políticas que son implementadas (y visto a la inversa las que no pasan el filtro) del sistema. En este aspecto podría ponerse el foco de atención en múltiples aspectos. Se puede ir desde hacer un análisis de los tipos de políticas en función de su carácter redistributivo a políticas por el grado de movilización, impregnación o carga ideológica, grado de control de la población, entre otras. Ocupa una especial importancia la retroalimentación del sistema político. En este aspecto atenderíamos al grado de capacidad de respuesta (responsiveness) del sistema político ante las demandas que se le han presentado. En este sentido la diferencia es, pues, de grado, de la medida en que las demandas son procesadas.

De estas dos perspectivas, consideramos más acertado centrarse en las entradas al sistema (inputs), y dentro de éstos, en un análisis de las estructuras de intermediación o los medios por los que se canalizan las demandas. Esta perspectiva nos permitirá analizar los sistemas políticos atendiendo a cómo se comportan en su procesamiento de las demandas y de los apoyos, siendo éstos nuestros indicadores de entradas (inputs).

Aun partiendo del caveat que hemos hecho en este apartado de que emplearemos el concepto de sistema político en lugar del de régimen, sin embargo, no hemos de olvidar el desarrollo que han tenido ambos conceptos y lo útil que pueden sernos las caracterizaciones que se han hecho en términos de régimen político, más aún cuando sus propios autores lo identifican con el propio sistema político. En este sentido, el concepto de sistema político, por su abstracción, nos permite comparar realidades políticas que son distintas si atendemos únicamente a los elementos institucionales. Esto es fundamental cuando se trata con sistemas autocráticos que carecen en muchas ocasiones de elementos institucionalizados, funcionando con estructuras de poder no regladas jurídicamente. Asimismo, incorpora al modelo de análisis a los actores, otro de los elementos clave en este estudio al tratar fundamentalmente con los militares no sólo en tanto que institución sino en cuanto actores que intervienen ocasionalmente en la arena política. Pero, al mismo tiempo, al tratar tan estrechamente los elementos institucionales que tradicionalmente se han asociado al concepto de régimen, es importante un concepto como el de sistema que delimita los elementos estáticos de aquéllos más dinámicos del sistema político. Por ello es preciso el concepto de sistema, pero en una aproximación menos abstracta que la que Easton nos ofrece para poder permitir la clasificación de los países $y$, consiguientemente, su comparación.

Por ello, si bien el concepto de sistema político nos ofrece un gran marco para generar un modelo de las relaciones políticas y establecer un marco de comparación a nivel global entre realidades que en muchas ocasiones son bien distintas, también este concepto tiene límites, algunos de ellos impuestos por su desarrollo mucho más centrado en explicaciones abstractas y centradas en cuestiones internas de los países y no entre países. Es decir, se trata de un concepto que no se ha usado de forma tan empírica para comparar entre países. Asimismo, y en relación con lo anterior, su uso está extendido, y los propios ejemplos de Easton son prueba de ello, para el análisis de las democracias ${ }^{4}$. Esto hace que el modelo no siempre haya sido visto como de interés para abordar el análisis de las autocracias y que haya sido poco prolijo en cuestiones de clasificación.

\subsection{Criterios para una tipología de los sistemas políticos}

La teoría de sistemas es una forma de comprender la política de manera dinámica, como un proceso continuo de demandas y apoyos (entradas) que dan lugar a decisiones (resultados) que activan al mismo tiempo una retroalimentación que da lugar a nuevas demandas y apoyos. No obstante, el concepto de sistema político se ha generalizado tanto que es la manera principal para hablar de las realidades políticas. Esa difusión del concepto de sistema político ha provocado que pierda carácter específico y ha llevado a una identificación con la realidad política más extendida que analizamos en Ciencia Política, la democracia. Este tipo de visión macro hace que desde este enfoque no se hayan prodigado las clasifica-

\footnotetext{
Casi todo el trabajo de corte más empírico de David Easton está centrado en estudios de casos relacionados con los Estados Unidos. Esto hace que su modelo se adapta muy bien a los sistemas democráticos, pero que no haya sido de mucho uso entre los comparativistas. Es, en este sentido, deudor de una tradición norteamericana que divide entre Política Comparada y el resto de la Ciencia Política en función de si se desea investigar los Estados Unidos o el resto de países.
} 
ciones de los sistemas políticos y menos con un carácter tan empírico como es el que ha ocurrido en el caso de los regímenes políticos. En este sentido, la aplicación que hacemos de la teoría general de sistema se despega del uso más habitual que ésta ha tenido en el pasado.

Por otra parte, si la perspectiva del sistema político adolece de un marcado carácter macro y abstracto tan alto, la aproximación de los autores que emplean el término de régimen político, por el contrario, ha llevado a la elaboración de tipologías en algunos casos muy ancladas en la realidad concreta del momento sin que puedan detectarse una línea de continuidad o cierta exhaustividad en los resultados. Como ya hemos apuntado, en nuestro caso emplearemos una aproximación sistémica para entender el conjunto del proceso, pero sin hacerla tan restringida que nos impida una aproximación concreta a los sistemas políticos y su clasificación. En concreto, esto significa que evitaremos que entre las categorías de la taxonomía haya una identificación directa entre casos y tipos, defecto del que han adolecido ciertas tipologías.

De todo el proceso que sigue el sistema político, consideramos que las entradas (inputs) son las que nos permiten abordar la clasificación de una manera más adecuada. Así será éste el criterio que usemos para clasificar los sistemas políticos. Un sistema de rendición de cuentas es un mecanismo mediante el cual los actores juzgan ex post facto los resultados políticos y dan o retiran su apoyo en función de cómo se ha dado respuesta a sus demandas. En los sistemas políticos democráticos los gobernantes son responsables ante los ciudadanos, ante quienes rinden cuentas y de quienes encuentran su fuente de apoyo a través de las elecciones, mientras que en otros sistemas la fuente de apoyo es distinta, bien sea la legitimidad dinástica, la estructura del partido, el carisma del líder o el apoyo del ejército. Centrando la clasificación de los sistemas políticos en la noción eastoniana de entradas podemos establecer un continuum entre los sistemas políticos que son democráticos y los que no lo son, atendiendo no sólo a cuántos ejercen el poder (o el control del mismo) como sería propio de una clasificación aristotélica, sino atendiendo también a qué tipos de actores apoyan a quienes toman las decisiones y cómo éstos últimos procesan las demandas. Esto proporciona un marco general de clasificación de los sistemas políticos y proporciona explicaciones más consistentes y profundas, pues disponemos de un criterio vertebrador de la clasificación. Si bien los resultados del sistema político son muy variados, por la vía de las entradas podemos limitar esta pluralidad a un conjunto reducido, pero razonablemente detallado de tipos.

En los autores precedentes vemos la necesidad de combinar elementos más formales con elementos de funcionamiento del sistema. Son estos últimos los que nos ayudarán más en la tarea clasificatoria. Las clasificaciones que manejamos de otros autores (Linz y Stepan, 1996; Morlino, 2009; Geddes, 1999; Hadenius y Teorell, 2007) entroncan bien con esta perspectiva metodológica. De cada uno de ellos sacaremos elementos que consideramos relevantes para inspirar nuestro esquema general. $\mathrm{Al}$ distinguir en función de quién ejerce el poder, cómo lo ejerce y de dónde parte éste, en estas clasificaciones prima el mecanismo por el que funciona el sistema político más que las formas jurídicas que lo definen. De esta manera, independientemente de la definición constitucional, estos autores atienden a quién ejerce el poder (un líder carismático, un militar, el partido único) y los distintos tipos de incentivos que conlleva el responder ante un electorado, una camarilla del partido, una junta militar o no tener a nadie ante el que responder. Los gobernantes, en estos distintos tipos de sistemas políticos, canalizan las demandas selectivamente y es este grupo ante el que responden, lo que nos resultará de utilidad para nuestra clasificación.

\subsection{Operacionalizando las variables de clasificación}

Hemos mencionado anteriormente que articularemos nuestra tipología en función del modo en que se procesan las entradas. Asimismo, dentro de los dos elementos que constituyen las entradas, demandas y apoyos, nos centraremos en la canalización de las demandas. Partiendo del análisis que hemos hecho de las clasificaciones de otros autores, para abordar la disección del modo de procesamiento de las demandas hemos identificado tres ejes relevantes que nos permiten abordar la clasificación conforme a criterios unificadores. El primero de ellos es el número de demandantes ante los que el sistema realmente responde. En cierto sentido, es una reconversión del criterio aristotélico de clasificación por el número de gobernantes, pero trasladado a los actores que tienen algún tipo de capacidad política, por pequeña que ésta sea. En esta categoría distinguiremos entre los sistemas que obedecen al criterio de uno solo, de unos pocos, de muchos o de todos. Si bien todos los sistemas políticos reciben demandas potencialmente del conjunto de la población que integra la unidad política, los sistemas políticos autocráticos se caracterizan por suprimir o reprimir las demandas, aunque no todos en la misma medida. Así, tal y como señala Linz (1970: 255), los autoritarismos se caracterizan por tener cierto grado de pluralismo político, económico y social, frente a los totalitarismos donde dicho pluralismo es inexistente. Esta limitación selectiva del pluralismo de demandas caracteriza en gran medida, a nuestro juicio, los sistemas políticos, y nos permite establecer una gradación entre sistemas.

El segundo de los ejes que hemos considerado relevante para articular nuestra tipología se refiere al tipo de legitimidad. Partiendo de la división tripartita de Weber entre legitimidad tradicional, legitimidad carismática y legitimidad racional legal, podemos finalmente proceder a distinguir entre sistemas que, de otra manera serían clasificados del mismo modo pero que, en su funcionamiento concreto, tienen características distintivas. Así, las autocracias unipersonales podrían dar lugar a marcar como el mismo fenómeno a las monarquías de corte casi absolutista que perduran en el mundo y a las dictaduras de oportunistas políticos que han llegado a hacerse con el poder. El funcionamiento de la tradición en el caso de las primeras hace que su comportamiento sea bien distinto a las segundas, en las que pesan otros factores 
a la hora de mantenerse en el poder. Asimismo, algunos sistemas autoritarios tienen una figura a su cabeza, pero que simplemente funciona como aglutinador de distintos intereses que modera, lo cual no es equiparable al control que ejercen algunos líderes por los que pasan todas las decisiones y que corresponden más al tipo personalista de sistema como veremos posteriormente.

El tercero de los ejes es el carácter militar o civil de la estructura que toma las decisiones. A pesar de la popularización de una línea de continuidad entre guerra y política ${ }^{5}$, lo cierto es que las dos se rigen por criterios muy distintos y suele llevar a equívoco partir del presupuesto de que la misma lógica que impera para los políticos lo hace igual para los militares. Tal y como señala Geddes (1999: 125) el tipo de motivaciones que hay detrás del militar son en gran medida de corte profesional sobre las aspiraciones netamente políticas de acceso al poder. Asimismo, el tipo de organización es completamente distinto, teniendo la organización militar una estructura rígida caracterizada por la jerarquía donde la demanda se canaliza de arriba abajo y el conflicto sólo puede ser resuelto por el superior. Por su parte, la política permite otros juegos, donde no hay una jerarquía a priori que someta al proceso o precisamente la política pueda ser el medio para subvertirla ${ }^{6}$. Así, existiendo reglas de funcionamiento tan dispares, resulta conveniente emplear este eje de división.

A continuación, mostraremos las categorías que resultan de la combinación de los tres ejes que hemos expuesto anteriormente. Primero ofrecemos la denominación del sistema político al que nos referimos y luego entre paréntesis mostramos cómo figurará dicho sistema en los gráficos y tablas que emplearemos y en el resto de apartados de este artículo.

1. Sistema político autocrático de gestión tradicional de las demandas (tradicional): es un sistema político en el que todas las atribuciones legislativas y ejecutivas se ejercen por un individuo o grupo reducido cuya legitimidad se fundamenta en su ascendencia, linaje o relación con algún fundamento religioso. Puede a su vez dividirse entre sistema político tradicional monárquico y oligárquico (en la práctica no existen los sistemas tradicionales democráticos hoy día), pero a nuestros efectos de análisis consideraremos ambos conjuntamente pues mantienen el principio de legitimidad igual y en la práctica resulta difícil discernir si el gobierno es unipersonal o si el monarca gobierna en función de lo que le transmite su camarilla más cercana.

\footnotetext{
De acuerdo con Von Clausewittz (De la guerra), "la guerra es una mera continuación de la política por otros medios". Este ejercicio consecutivo de guerra y política ha llevado con frecuencia a confundir ambos fenómenos, que no son lo mismo. Si bien Clausewitz pone de manifiesto que la guerra es la consecuencia del fracaso de la política, con frecuencia se ha invertido la relación y se ha llevado a la política el escenario bélico, cuando esto implica precisamente destruir el concepto de política, que no se caracteriza por la supresión del conflicto, sino por su canalización.

6 Por ejemplo, no han sido infrecuentes los golpes de Estado dirigidos por oficiales que no ocupaban la más alta jerarquía y cuyo golpe les catapultó no sólo política sino profesionalmente también.
}

2. Sistema político autocrático de gestión de las demandas a través de un líder carismático (personalista): es un sistema político en el que la toma de decisiones depende de un único individuo que concentra los poderes ejecutivo y legislativo, sin ningún contrapeso de otros elementos y en el que la promoción política depende de la dispensa de favores por parte del líder carismático, quien es el encargado de satisfacer a los distintos grupos que lo apoyan para mantenerse en el poder.

3. Sistema político autocrático de gestión de las demandas a través de un cuerpo colegiado militar (militar): es un sistema político en el que o bien el poder ejecutivo y legislativo recae de forma colegiada en un cuerpo de oficiales del ejército o bien dicho cuerpo ejerce una función estrecha de monitoreo sobre el ejecutivo y legislativo mediante instituciones establecidas al uso que son las encargadas de procesar las demandas al sistema.

4. Sistema político autocrático de gestión de las demandas a través de un aparato hegemónico civil (partido único): es un sistema político en el que la toma de decisiones depende de un único cuerpo colectivo, sea un partido único configurado como tal o un grupo organizado y estructurado, que se encarga de controlar la promoción política de sus integrantes y canalizar las demandas de la sociedad a través del aparato del partido, que viene a superponerse sobre otras estructuras legales.

5. Sistema político autocrático de gestión de las demandas a través de un aparato hegemónico cívico-militar (ejército partido): es un sistema político en el que las decisiones son tomadas por un aparato burocrático político militar que controla el gobierno y dirige la promoción política y militar, y la sucesión en la dirección del gobierno, canalizando las demandas a través de los mecanismos a disposición de dicho aparato burocrático. A diferencia de los sistemas militares donde las estructuras militares se superponen a las civiles, se produce una simbiosis entre partido y ejército, donde el ascenso en una y otra está relacionado. Si bien pueden existir estructuras civiles, la decisión última pasa por un cuerpo de oficiales. En este sistema las Fuerzas Armadas, a través de sus procesos de selección interna, nutre de cuadros de decisores políticos.

6. Sistema político autocrático de gestión difusa de las demandas (autoritario): es un sistema político caracterizado por un pluralismo limitado en el que esporádicamente pueden producirse elecciones como mecanismo de legitimación de la élite gobernante, pero que carece de garantías de libertad para la oposición política ni posee verdaderos mecanismos de alternancia en el poder. Puede ser una fase transitoria en la evolución hacia una democracia o en su deterioro hacia sistemas políticos autoritarios de otro signo. Se caracteriza por una amplia coalición de facciones que excluyen a determinados actores del juego político, donde no hay un único mecanismo centralizado de canalización de las demandas ni un líder con la autoridad suficiente para ser el que controle la gestión de las peticiones de los distintos grupos que apoyan el sistema otorgando favores y controlando el acceso. 
7. Sistema político democrático imperfecto (democracia mínima): es un sistema político en el que las decisiones son tomadas por el principio de la mayoría, que realiza elecciones regularmente pero que presenta problemas en el respeto del ejercicio de sus derechos por parte de las minorías, notablemente por la preeminencia en el gobierno de determinados grupos o por la canalización selectiva y apartamiento de determinados grupos, excluidos de la participación tanto política como, en ocasiones, electoral. En determinados casos puede tratarse simplemente del paso perentorio durante la transición a un sistema político democrático o del afloramiento de conflictos agudos que llevan al deterioro hacia formas autocráticas.

8. Sistema político democrático (democracia): es un sistema político en el que las decisiones son tomadas por el principio de la mayoría con el respeto de la minoría a través de elecciones libres y regulares y competitivas que deciden ejecutivo y legislativo y permiten la promoción de todas las demandas con el respeto de la minoría a que ésta pueda convertirse en un futuro en mayoría por medios pacíficos. En este sistema todos los integrantes del sistema tienen la posibilidad de realizar una tarea de fiscalización sobre las decisiones de los representantes electos, existiendo una estructura de rendición de cuentas que pasa no sólo por las elecciones, sino por mecanismos de control societal. Asimismo, la configuración de la estructura del sistema pone en marcha mecanismos completos de control entre unos poderes y otros. Se diferencia del sistema político democrático imperfecto por que ha completado de desarrollar todos estos mecanismos y en él no se producen exclusiones a la participación de ningún tipo.
9. Sin gobierno efectivo o fallido: es un sistema político fallido en el que, debido a invasiones extranjeras, fragmentación del poder o guerra civil, no hay una única autoridad ejerciendo el control sobre gran parte del territorio. Nos sirve a modo de categoría residual para sistemas políticos en crisis internas generadas por la violencia y donde no se pueda afirmar que hay un único sistema político ni que las partes cuentan con la autonomía suficiente como para considerarse sistemas políticos aparte.

En el gráfico 1 mostramos la clasificación que hemos detallado anteriormente teniendo presentes el eje del número y de la legitimidad. El tercer eje, constituido por el carácter militar, resultaría de separar los sistemas militares y de ejército partido del resto de sistemas que aquí se presentan. De esta manera podemos observar que a medida que el tipo de legitimidad deriva hacia modelos con un criterio legal racional se observa una ampliación de la base de personas ante las que responde el sistema político directamente. Dicho crecimiento es de carácter exponencial, es decir, que a medida que el sistema bascula hacia fórmulas en las que los criterios de legitimidad están más basados en términos que coinciden con la legalidad y racionalidad del sistema, el número de personas ante los que tienen que responder los gobernantes no crece linealmente, sino en múltiplos exponenciales. Así, a medida que son más abiertos a las demandas los sistemas deben desarrollar mayor inclusión.

\subsection{Marco espacial y temporal}

En el apartado anterior hemos expuesto cuáles han sido los criterios que nos han servido de base para elaborar

Gráfico 1. Clasificación de los sistemas políticos según el procesamiento de entradas.



Fuente: Elaboración propia. 
una tipología de los sistemas políticos. Como resultado de aplicar los tres filtros que hemos elegido (número, legitimidad y carácter civil o militar) hemos obtenido nueve categorías resultantes. Para hacer operativas estas categorías es preciso concretarlas tanto en el espacio como en el tiempo. Con este ejercicio podemos mostrar que esta tipología abarca las diferentes realidades políticas de todos los países del mundo.

Por tanto, a la hora de determinar nuestro marco espacial hemos decidido aplicar nuestra tipología al universo de casos posible, es decir, todos los países del mundo. Esto permite contrastar la validez del empleo de la tipología al ver si cumple con el criterio de exhaustividad que nos habíamos marcado para este estudio. Con ello ponemos a prueba la tipología frente a un variado espectro de sistemas políticos.

Por otra parte, para nuestro marco temporal hemos fijado el período entre 1960 y 2006 . Hemos elegido este marco temporal por ser la fecha de 1960 la primera desde la que se disponen datos más fiables a la caída de los grandes imperios coloniales y el inicio de los procesos de independencia africanos y asiáticos, de manera que disponemos de un universo de casos mayor y hay menos perturbaciones por el cambio de fronteras. 2006 nos ofrecía una fecha con datos consolidados para poder trabajar con mayor comodidad al haber una década de margen.

A la hora de realizar nuestros cómputos, hemos fijado la unidad de medida de país-año. Esto nos permite individualizar los casos y ponerlos al mismo nivel para evitar que los países más inestables computen más veces que los países más estables. Dado que nuestro marco temporal abarca desde 1960 hasta 2006, si un país es una democracia durante cuarenta y seis años, aparecerá computado cuarenta y seis veces. Esto hace que todos los países aparezcan el mismo número de veces, cosa que no ocurriría si lo que computásemos fueran distintos tipos de sistemas políticos ${ }^{7}$.

\section{Clasificación de los sistemas políticos en perspectiva comparada}

En este apartado presentaremos tanto el resultado de aplicar nuestras categorías de análisis como una comparación con el trabajo realizado por otros autores para clasificar los sistemas políticos. En primer lugar, procederemos a mostrar cómo se refleja nuestra tipología propia para, a continuación, proceder a un análisis comparado con otras tipologías que realizan un análisis a gran escala.

Si el criterio de cómputo fueran los sistemas, en tal caso algunos países aparecerían más veces que otros. Por ejemplo, países como Dinamarca, que han sido democracias todo el período, serían computados una vez, mientras que países como Afganistán, que han sufrido múltiples cambios, serían computados múltiples veces. No existe realmente una gran diferencia entre ambos métodos en lo que aquí respecta, pero ha de tenerse en cuenta a la hora de juzgar las tablas del apartado 4.2. Si discrepamos con otros autores en casos cuyos sistemas son muy duraderos en el tiempo frente a otros sistemas que apenas duran un año, el grado de discrepancia será mayor numéricamente, a pesar de que se trate de sólo una discrepancia en ambos casos.

\subsection{Resultado de la aplicación de las categorías de análisis}

En este artículo, hemos procedido a realizar una clasificación de cada uno de los sistemas políticos año a año, asignando una de las precedentes nueve categorías a cada caso, sin que hubiera excepciones o categorías especiales ad hoc. En los anexos puede consultarse toda la documentación relativa a esta clasificación, así como un detalle anual de cómo se ha clasificado cada uno de los casos objeto de este estudio. Por simplificar la exposición, y para ilustrar dichos resultados sin necesidad de consultar los anexos, se presenta a continuación un mapa que recoge los resultados de nuestra clasificación para el año 2006.

\subsection{Comparación de la tipología con la desarrollada por otros autores}

En este apartado realizaremos una evaluación de la aplicación de esta clasificación, centrándonos en las divergencias que detectamos con respecto a otros autores. Consideramos que una divergencia es relevante cuando clasificamos un sistema como democrático y para otros autores es considerado una dictadura. Asimismo, son divergencias relevantes cuando nosotros señalamos que el sistema tiene un carácter civil y no es clasificado así por otros autores.

De esta manera podemos encuadrar mejor la clasificación que hemos adaptado dentro del marco de otros estudios que tienen un alcance similar o idéntico al nuestro, es decir, que cubren todos los países del mundo dentro del marco temporal ${ }^{8}$ que hemos elegido. Por ello en los autores de referencia emplearemos aquellos que proceden a hacer una distinción no sólo entre democracias y autocracias, sino que distinguen entre autocracias. Nos encontramos con dos clasificaciones con un alcance parecido Cheibub et al. (2009) y Geddes et al. (2014) ${ }^{9}$.

En la siguiente tabla mostramos el resultado de comparar nuestra clasificación con la realizada por Cheibub et al. (2009). En su caso, esta clasificación parte de la idea original de un mundo dividido entre democracias y no democracias. Posteriormente se clasifica a las democracias por el modo en que se elige el ejecutivo y su relación con el legislativo, dejándonos la división entre democracias parlamentarias, mixtas y presidenciales. En cuanto a los regímenes no democráticos estos autores los encierran bajo la denominación de dictadura, distinguiendo entre el carácter del gobernante civil, militar o de la realeza.

El marco temporal hace que debamos excluir de nuestra comparación el trabajo de Hadenius y Teorell (2007) que, si bien realiza también un análisis exhaustivo de todos los países distinguiendo al interior de los regímenes políticos, no tiene un marco temporal igual al nuestro pues su análisis comienza en 1974. Sin embargo, cuando ha habido que comparar nuestra clasificación con la de otros autores, hemos recurrido en ocasiones a Hadenius y Teorell, como referencia. En Geddes (1999) podemos encontrar una primera aproximación a la clasificación de los regímenes políticos. La segunda clasificación de Geddes es más extensa en el número de casos que aborda, pero también supone una revisión de su clasificación original. Para orientar nuestras propias decisiones hemos procurado tener en cuenta ambas, sobre todo en sus divergencias 
Gráfico 2. Mapa de los sistemas políticos según el procesamiento de entradas.

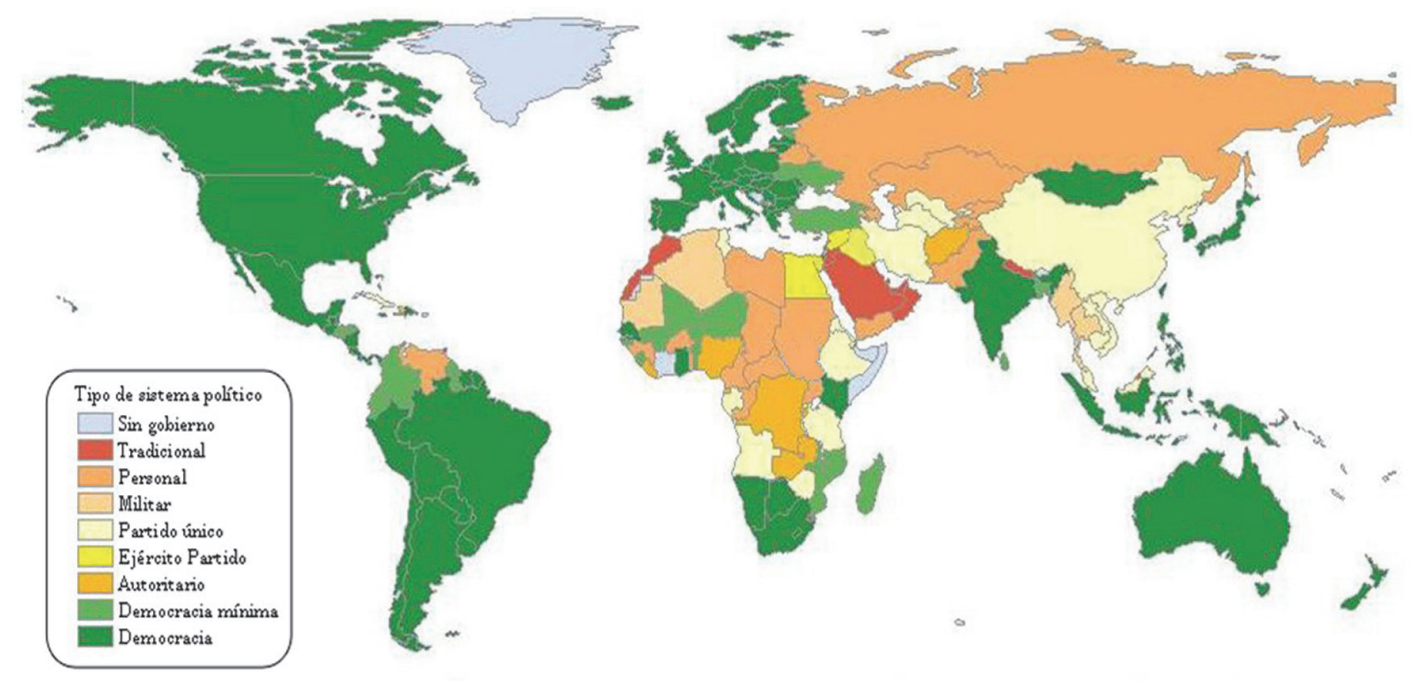

Fuente: Elaboración propia.

La tabla 1 muestra esta comparación en detalle. La unidad de base de la observación es el año país, lo que significa que cada caso reflejado es un país en un año dado. En las filas hemos situado nuestra clasificación, mientras que en las columnas encontramos la clasificación elaborada por Cheibub et. (2009). Esta tabla puede leerse tanto de izquierda a derecha como de arriba abajo. De la primera manera podemos ver, por ejemplo, de todos los países que nosotros clasificamos como de sistema político tradicional, cuáles son clasificados por estos autores como democracias parlamentarias, mixtas y presidenciales o dictaduras civiles, militares o de la realeza. A la inversa, leyendo por columnas, por ejemplo, de los casos clasificados por Cheibub et al. (2009) como democracias parlamentarias veremos cuáles son según nuestra clasificación sistemas fallidos, tradicionales, personalistas, militares, de partido único, de ejército partido, autoritarios, democracias mínimas o democracias.

Nuestro universo de estudio está compuesto por 6.823 casos, es decir, 6.823 observaciones de distintos países ${ }^{10}$ en un año dado. De todos ellos encontramos divergencias importantes en 438 casos, alrededor de un 7\% de discrepancias sobre el universo total de casos. De estos 438 casos, la mayor parte, 232 casos, proviene de la diferencia entre sistemas que nosotros clasificamos como democráticos (bien de democracia mínima o completa) y que Cheibub et al. clasifican como dictaduras civiles. Estos casos son eminentemente los relacionados con los países en los que hay un partido dominante (generalmente una coalición preelectoral) que ha ganado las sucesivas elecciones desde la independencia del país. Cheibub et al. parten del concepto de que para ser clasificado como democracia es preciso que se produzca o haya producido efectivamente un cambio en la titularidad del poder, característica que nosotros no com-

10 Como se mencionaba anteriormente, cada país puede repetirse hasta un total de cuarenta y seis veces dado que nuestro marco temporal abarca desde 1960 hasta 2006. Algunos países se repiten menos, bien porque se crean con posterioridad, bien porque desaparecen como tales, como en el caso de Alemania Oriental, Checoslovaquia, Vietnam del Sur, entre otros. partimos. En concreto para Cheibub et al. países como Botsuana o Namibia deberían considerarse como dictaduras a pesar de que, de acuerdo con todos los estándares internacionales y observadores de las elecciones, dichos procesos electorales se han considerado limpios y transparentes. Al margen de esto otras fuentes como puede ser Freedom House, clasifican estos países como respetuoso de las libertades civiles y políticas. Es más, por otra parte, una aplicación estricta de este criterio podría hacer que países como África del Sur, donde predomina la misma cultura política de grandes coaliciones preelectorales, debieran ser clasificados como dictaduras civiles también si tenemos en cuenta como cómputo sólo el período constitucional democrático post-apartheid, el único que realmente debería computar de acuerdo con la regla de Cheibub et al., donde el Partido del Congreso Africano ha ganado sistemáticamente todas las elecciones, sin que se haya producido ninguna alternancia. No obstante, por motivos que no quedan reflejados, África del Sur es clasificada como democracia, hecho que no ocurre con sus vecinos del norte.

Otro tipo de discrepancias son aquéllas en las que, a nuestro juicio, el criterio de Cheibub et al. ha clasificado como democracia a sistemas que no lo son, generalmente por encontrarse en una situación de conflicto, porque el deterioro democrático se produjo antes de que el cambio fuera formal o porque, aunque formalmente existen reglas de juego democráticas, éstas no se respetan. En cuanto a las situaciones de conflicto, por ejemplo, codifican países como Sierra Leona como democracia durante el período de guerra civil al final de los años noventa, mientras que en estos casos hemos optado por considerarlo como un sistema fallido. En otras ocasiones sistemas políticos que comienzan formalmente como democracias derivan en ejercicios autoritarios del poder, hasta el punto de que hay denuncias de la oposición sobre la transparencia de las elecciones y del proceso político. Por ejemplo, éste es el caso de Uruguay a principios de los años setenta, lo cual terminaría derivando en una dictadura militar, deriva autoritaria gradual que estos autores no reconocen como tal. 
Tabla 1. Comparación con la clasificación de Cheibub et al., (2009).

\begin{tabular}{|l|c|c|c|c|c|c|}
\cline { 2 - 7 } & \multicolumn{6}{c|}{ Régimen político (Cheibub et al., 2009) } \\
\cline { 2 - 7 } & $\begin{array}{c}\text { Democracia } \\
\text { parlamentaria }\end{array}$ & $\begin{array}{c}\text { Democracia } \\
\text { mixta }\end{array}$ & $\begin{array}{c}\text { Democracia } \\
\text { presidencial }\end{array}$ & $\begin{array}{c}\text { Dictadura } \\
\text { civil }\end{array}$ & $\begin{array}{c}\text { Dictadura } \\
\text { militar }\end{array}$ & $\begin{array}{c}\text { Dictadura de } \\
\text { la realeza }\end{array}$ \\
\hline Fallido & 1 & 0 & 5 & 106 & 14 & 1 \\
\hline Tradicional & 0 & 0 & 0 & 8 & 1 & 507 \\
\hline Personal & 20 & 26 & 27 & 349 & 583 & 0 \\
\hline Militar & 26 & 1 & 20 & 25 & 281 & 0 \\
\hline Partido único & 26 & 3 & 10 & 1302 & 156 & 0 \\
\hline Ejército Partido & 0 & 1 & 0 & 6 & 351 & 0 \\
\hline Autoritario & 31 & 2 & 46 & 81 & 15 & 5 \\
\hline Democ. mínima & 134 & 110 & 264 & 90 & 9 & 0 \\
\hline Democracia & 1174 & 406 & 457 & 142 & & 0 \\
\hline
\end{tabular}

Fuente: Elaboración propia a partir de Cheibub et al. (2009).

A veces una situación de conflicto va aparejada a un liderazgo personalista, como es el caso de Croacia durante la década de los noventa, inmersa en plena guerra, bajo un liderazgo omnipresente como el de Tudjman, clasificado como democracia según Cheibub et al., en lo que discrepamos. Por último, hay una serie de países puntuales en los que discrepamos de su criterio, apreciando en nuestro caso ciertas características no democráticas donde estos autores no lo detectan como tal. Dichas discrepancias pueden observarse en los anexos.

En la siguiente tabla podemos ver la comparación de nuestra clasificación con la que hacen Geddes et al. (2014). En el caso de esta clasificación se parte de la original de Geddes (1999), que divide los regímenes autoritarios en personalistas, de partido único y militares conforme a los distintos tipos de incentivos que enfrentan en los procesos de apertura democrática. Dichos regímenes, a su vez, permiten ver hibridaciones en todas las combinaciones lógicas posibles. Junto a este trabajo original, planteado para un conjunto de países que no abarcaba todos los países del mundo, en un trabajo posterior se añaden nuevas categorías que lo completan, como los regímenes monárquicos y oligárquicos. Dado que el enfoque de estos autores se centra en los regímenes que denominan autoritarios, el resto de categorías se convierten así en categorías residuales. Esto hace que democracias, regímenes en situación de guerra, conflicto o simplemente sistemas fallidos entren dentro de la misma categoría. Además, hay determinados "micro-Estados" que son excluidos de la base de datos pero que nosotros sí incluimos. Como en el caso anterior esta tabla puede ser leída tanto de izquierda a derecha como de arriba abajo.

Tabla 2. Comparación entre la clasificación por sistema político y por régimen (Geddes et al., 2014).

\begin{tabular}{|c|c|c|c|c|c|c|c|c|c|c|c|c|}
\hline & \multicolumn{12}{|c|}{ Régimen político (Geddes et al., 2014). } \\
\hline & Dem. & $\begin{array}{l}\text { Milit. } \\
\text { indirct }\end{array}$ & Mil. & $\begin{array}{c}\text { Mil. } \\
\text { perso. }\end{array}$ & Monarq. & Perso. & Olig. & $\begin{array}{c}\text { Partido } \\
\text { único }\end{array}$ & $\begin{array}{l}\text { Partido } \\
\text { militar }\end{array}$ & $\begin{array}{c}\text { Partido } \\
\text { personal }\end{array}$ & $\begin{array}{l}\text { Partido } \\
\text { personal } \\
\text { militar }\end{array}$ & $\begin{array}{c}\text { Sin } \\
\text { cubrir }\end{array}$ \\
\hline Sin gob. & 0 & 0 & 1 & 1 & 1 & 19 & 0 & 2 & 1 & 1 & 0 & 86 \\
\hline Trad. & 0 & 0 & 0 & 0 & 377 & 0 & 0 & 4 & 0 & 0 & 0 & 132 \\
\hline Perso. & 11 & 0 & 18 & 80 & 11 & 823 & 0 & 1 & 0 & 0 & 0 & 44 \\
\hline Milit. & 0 & 7 & 225 & 55 & 0 & 26 & 0 & 0 & 2 & 1 & 0 & 13 \\
\hline Part. único & 8 & 0 & 1 & 0 & 1 & 11 & 29 & 1053 & 0 & 293 & 0 & 94 \\
\hline Ejé. Part. & 0 & 1 & 0 & 64 & 2 & 16 & 0 & 0 & 112 & 11 & 149 & 0 \\
\hline Autorit. & 14 & 14 & 4 & 7 & 4 & 22 & 0 & 28 & 1 & 2 & 3 & 50 \\
\hline Dem. mín. & 510 & 11 & 10 & 2 & 2 & 6 & 3 & 36 & 0 & 0 & 3 & 24 \\
\hline Dem. & 2027 & 0 & 6 & 2 & 0 & 1 & 2 & 99 & 0 & 0 & 0 & 43 \\
\hline
\end{tabular}


De los 6.823 casos que tiene nuestra base de datos, nuestra clasificación y la de estos autores coincide plenamente en 5.366 registros. A estos registros cabe sumar otros 486 casos que nosotros incluimos en nuestro estudio y que no están presentes de manera directa en el suyo. Dichos registros se mezclan con la categoría residual de democracia para este estudio, habiendo en ella tanto sistemas políticos democráticos como fallidos. En total, pues cerca de un $85 \%$ de los registros coinciden entre ambas clasificaciones. A estos casos cabe añadir otros 100 casos que se corresponden a situaciones de conflicto o guerra civil y Estados fallidos que estos autores no clasifican tampoco. Esto nos deja con 871 discrepancias, que suponen un $12 \%$ de los casos totales.

La principal diferencia entre ambas clasificaciones corresponde a los regímenes híbridos. Como ya hemos manifestado anteriormente, consideramos que la hibridación no es la mera adición de características y que el nuevo componente tiene características propias distintivas más allá de la suma de las partes. En este sentido, las características que establecen Geddes et al. como de regímenes de partido único, personalistas y militares $\mathrm{u}$ otras combinaciones entre estos elementos han recibido un trato distinto. Consideramos que no existe la combinación entre un sistema de partido único o uno personalista, sino que hay que juzgar en cada caso si nos encontramos ante un sistema personalista o de partido único. En todo sistema hay un liderazgo, por débil o formal que sea, y en los sistemas de partido único esto no deja de ser así, más bien al contrario. Esto nos ha llevado en muchos casos a clasificar los sistemas como de partido único exclusivamente, a pesar de los elementos de personalismo, por la propia pervivencia del partido a sus líderes y su capacidad para articular las sucesiones más allá de los deseos del líder concreto. En este sentido, en casos como el de Cuba, clasificado como régimen personalista y de partido único, nosotros hemos enfatizado el papel protagonista del partido. Algo parecido nos ha ocurrido a la hora de tratar los regímenes de partido único, personalista y militar, que han terminado subsumidos en sistemas de ejército partido u otros en función de las circunstancias. En esta categoría de ejército partido hemos incluido sistemas como el Egipto de Nasser, donde los militares han servido de correa de transmisión del poder, actuando en la promoción de nuevos líderes que requerían de su aquiescencia. El carácter estable de la relación la diferencia de las juntas, que tienen una vida efímera y no tienen penetración social alguna.

Otro factor en el que divergen ambas clasificaciones, como ya vimos para el caso de Cheibub, es el trato a los casos de partido dominante. Ya vimos que, si se respetan las normas de juego democráticas, hemos clasificado dichos países como democracias. Para Geddes et al. (2009) casos como los de Namibia o Botsuana merecen el trato de regímenes que denominan "basados en un partido". Si bien no llegan a denominarlos dictaduras como Cheibub et al. tampoco los consideran como democracias.

Otra diferencia importante viene de la mano de nuestra categoría sistemas autoritarios, que no tiene un correlato concreto en Geddes et al. (2014). En dicha ca- tegoría, según la definición que hemos proporcionado anteriormente, hemos clasificado los sistemas autocráticos que tienen cierto pluralismo, pero donde no hay un líder personalista ni una junta militar que dominen la esfera política. Asimismo, en momentos de transición hemos optado por esta denominación para sistemas en proceso de democratización pero que todavía no cumplen los requisitos para ser democracias. Por último, hay una serie de discrepancias puntuales numéricamente elevada que se debe al modo en que se han codificado los años, haciendo que en ocasiones detectemos en la base de Geddes et al. un año de desvío no sólo con respecto a nuestra base de datos sino a la de otros autores que hemos consultado.

\section{Conclusiones}

En primer lugar, en este artículo hemos comparado los conceptos de régimen y de sistema político y hemos visto las distintas aproximaciones que se han realizado al respecto. Hemos optado por un enfoque sistémico pues el régimen político describe sólo una parte del proceso político (o directamente se confunde con el propio concepto de sistema político, como hemos visto, según algunos autores). El concepto de sistema político nos muestra el marco de objetivos, normas y estructuras en el que se desenvuelven los actores para dar respuestas a las demandas, pero, como hemos visto en otros autores que definían régimen político latu sensu, hay elementos importantes del juego político que se quedarían fuera si atendemos exclusivamente al marco normativo (ya sea formal e informal), como es la interacción de los actores con objetivos, normas y estructuras y de éstos a su vez con las demandas. No obstante, esta apuesta por el enfoque sistémico la hacemos procurando evitar una excesiva abstracción que no nos permite abordar la realidad directamente.

Por estos motivos, en segundo lugar, hemos procedido a describir los desarrollos teóricos que se han realizado desde los estudios que han tomado como base el régimen político. Esto nos ha sido de gran utilidad pues enriquecen con su experiencia el tipo de análisis que podemos realizar nosotros en este estudio. A partir del concepto de régimen en un sentido amplio y los estudios de otros autores, añadimos categorías cuyo uso ha sido ya contrastado empíricamente tanto a través de estudios de caso, como estudios comparados y estadísticos.

En tercer lugar, dentro del enfoque sistémico hemos identificado dos momentos: el sistema como procesamiento de demandas y el sistema como productor de resultados y el proceso de retroalimentación consiguiente. Dividir el sistema en estos dos momentos nos permite buscar en cuál de ellos podemos concentrar nuestra categorización de los sistemas para no multiplicar las tipologías, lo cual terminaría quitándole a este ejercicio de clasificación todo poder generalizador. Finalmente hemos determinado que emplearemos el sistema político desde la perspectiva del procesamiento de demandas como centro de nuestro ejercicio clasificatorio. Esto se debe a que los resultados del sistema político pueden ser 
muchos y muy variados. Así, podremos atender al tipo de políticas redistributivas que se producen, al tipo de movilización que genera el sistema, al grado de pluralismo que acogen sus resultados, entre otros. Por ello, mientras los resultados son muy diversos, el modo en que se procesan las demandas podemos reducirlo a un conjunto de factores mucho más limitado.

Tras centrarnos en el modo en que se procesan las demandas, en cuarto lugar, hemos aplicado tres criterios de clasificación al sistema político, entendido éste como un flujo constante de interacción. El primero de ellos es el número efectivo de actores y grupos de intermediación y articulación de demandas ante los que responde el sistema. El segundo es el principio de legitimidad frente a los apoyos al sistema. El tercero es el carácter civil o militar de los dirigentes del sistema. A partir de estos ejes hemos elaborado un cuadro de categorías que resultan de la aplicación de las dimensiones que acabamos de enunciar. Esto nos da los siguientes tipos de sistemas: tradicional, personalista, militar, partido único, ejército partido, autoritario, democracia mínima, democracia $y$ fallido. Hemos observado cómo entre ellos hay una línea de continuidad en función del número y el tipo de legitimidad que los sustenta. Para comprobar estos datos hemos puesto a prueba nuestras categorías analíticas y hemos procedido a aplicarlas a todos los países del mundo entre 1960 y 2006, para poder obtener un cuadro completo de cómo resultaría la aplicación de esta tipología. Dicho cuadro se ha comparado con el ofrecido con otros autores y se han justificado las divergencias.

\section{Bibliografía}

Almond, G. (1966). "Political Theory and Political Science", en American Political Science Review, vol. 60, n4, pp. 869-879.

Almond, G., Powel, G, B. (1981). Comparative Politics: A Developmental Approach. Boston: Brown.

Badie, B., Birnbaum, P., Braud, P., Hermet, G. (1996). Dictionnaire de la Science Politique et des institutions politiques. Paris : Armand Colin.

Bobbio, N., Matteuci, N., Pasquino, G. (2011). Diccionario de política. Siglo XXI. México.

Cheibub, J. A., Gandhi, J., Vreeland, J. R. (2009). "Democracy and dictatorship revisited", en Public Choice, vol. 143, n 1-2, pp. 67-101.

Chevalier, J. (1996). Institutions politiques. Paris : L.G.D.J.

Clausewitz, C. V. (2010). De la guerra. Madrid: Tecnos.

Duverger, M. (1970). Instituciones politicas y Derecho Constitucional. Barcelona: Ariel.

Easton, D. (1953). The political system. An inquiry into the state of Political Science. Nueva York, Alfred A. Knopf.

Easton, D. (2006). Esquema para el análisis político. Buenos Aires: Amorrortu editores.

Engels, F., Marx, C. (2014). El Manifiesto Comunista. Madrid: Alianza.

Freedom House (2016). Freedom in the world. Disponible en https://freedomhouse.org (Consultado, 25/10/2019).

The Economists. (2016). Democracy Index 2015.

Disponible en http://www.eiu.com/public/topical_report.aspx?campaignid=DemocracyIndex2015 (Consultado, el 25/10/2019).

Geddes, B. (1999). "What do we know about democratization after twenty years?", en Annual Review of Political Science, vol. 2, pp. 115-144.

Geddes, B., Wright, J., Frantz, E. (2014). “Autocratic breakdown and regime transitions”, en Perspectives on Politics, vol. 12, $\mathrm{n}^{\mathrm{o}} 2$, pp 313-331.

Gremy, J. P y Le Moan, M. J. (1977). “Analyse de la démarche de construction de typologies dans les sciences sociales”, en Informatique et Sciences Humaines, $\mathrm{n}^{\circ} 35$, pp. 3-77.

Hadenius, A., y Teorell, J. (2007). "Pathways from authoritarianism”, en Journal of Democracy, vol. 18, n.1, pp. $143-157$.

Linz, J. J. (1970). “An authoritarian regime: The case of Spain”, en Allardt, E. and Rokkan, S. (eds.). Mass politics: Studies in political sociology. Nueva York: Free Press.

Linz, J. J., y Stepan, A. (1996). Problems of democratic transition and consolidation: Southern Europe, South America, and PostCommunist Europe. Baltimore: Johns Hopkins University Press.

Mann, M. (1993). States, war and capitalism. Cambridge: Blackwell.

Marshall, M. G. y Jaggers, K. (2007). "POLITY IV PROJECT. Political regime characteristics and transitions, 1800-2007”. Disponible en: http://www.systemicpeace.org/. (Consultado, el 10 de junio de 2012).

Miguel, J. M. de; y Martínez-Dordella, S. (2014). "Nuevo índice de democracia", en Revista Española de Investigaciones Sociológicas, $\mathrm{n}^{\mathrm{0}} 146$, pp. 93-140.

Morlino, L. (1988). "Las democracias”, en Pasquino, G. (comp.). Manual de Ciencia Política. Madrid: Alianza Universidad.

Morlino, L. (2009). Democracias y democratizaciones. Madrid: CIS.

Paniagua, J. L. (1990). "Los regímenes políticos y la organización del Estado", en Cotarelo, R., y Paniagua, J. L. (comps.). Introducción a la Ciencia Política. Madrid: UNED.

Skaaning, J. D. (2006). "Political regimes and their Changes: A conceptual framework", en Center on Democracy. Development and The Rule of Law Working Papers, $\mathrm{n}^{\circ} 55$.

Vargas, A. (1998). "Notas sobre los conceptos de sistema y régimen político”, en Estudios Políticos, nº 13, pp. 157-180. Medellín. 